\title{
Transport mechanisms in silicon heterojunction solar cells with molybdenum oxide as a hole transport layer
}

\author{
R. García-Hernansanz ${ }^{\mathrm{a}, *}$, E. García-Hemme ${ }^{\mathrm{a}}$, D. Montero ${ }^{\mathrm{a}}$, J. Olea ${ }^{\mathrm{a}}$, A. del Prado ${ }^{\mathrm{a}}$, I. Mártil ${ }^{\mathrm{a}}$, \\ C. Voz ${ }^{\mathrm{b}}$, L.G. Gerling ${ }^{\mathrm{b}}$, J. Puigdollers ${ }^{\mathrm{b}}$, R. Alcubilla ${ }^{\mathrm{b}}$ \\ a Dept. de Física Aplicada III (Electricidad y Electrónica), Univ. Complutense de Madrid, 28040 Madrid, Spain \\ ${ }^{\mathrm{b}}$ Departament d'Enginyeria Electrònica. Universitat Politècnica de Catalunya, 08034 Barcelona, Spain
}

A R T I C L E I N F O

\section{Keywords:}

Molybdenum oxide

Multitunneling

Gap states

Heterocontact

\begin{abstract}
A B S T R A C T
Heterojunction solar cells based on molybdenum sub-oxide $\left(\mathrm{M}_{\mathrm{o}} \mathrm{O}_{\mathrm{x}}\right)$ deposited on $\mathrm{n}$-type crystalline silicon have been fabricated. The hole selective character of $\mathrm{M}_{\mathrm{o}} \mathrm{O}_{\mathrm{x}}$ is explained by its high workfunction, which causes a strong band bending in the Si substrate. This bending pushes the surface into inversion. In addition, the substoichiometry of the evaporated $\mathrm{M}_{\mathrm{o}} \mathrm{O}_{\mathrm{x}}$ layers leads to a high density of states within the bandgap. This is crucial for charge transport. The J-V electrical characteristics at several temperatures were analysed to elucidate the dominant charge transport mechanisms of this heterojunction structure. We have identified two different transport mechanisms. At low bias voltage, transport is dominated by hole tunnelling through the $\mathrm{M}_{\mathrm{o}} \mathrm{O}_{\mathrm{x}}$ gap states. At higher voltage the behaviour is similar to a Schottky junction with a high barrier value, due to the high $\mathrm{M}_{\mathrm{o}} \mathrm{O}_{\mathrm{x}}$ work function. These results provide a better understanding of the hole selective character of $\mathrm{M}_{\mathrm{o}} \mathrm{O}_{\mathrm{x}} / \mathrm{n}$-type silicon heterocontacts, which is key to further improve this new kind of solar cells.
\end{abstract}

\section{Introduction}

The present record energy conversion efficiency of silicon-based solar cells is $26.3 \%$ [1], which is close to the Shockley-Queisser limit for a single junction silicon solar cell [2]. Such a high efficiency has been achieved by Kaneka combining the HIT (Heterojunction with Intrinsic thin Layer) concept with an interdigitated back contact (IBC) structure. This record efficiency exceeds by $1 \%$ the best silicon homojunction solar cells [3]. Nevertheless, conventional silicon p-n junctions still dominate the solar cell market owing to their simpler fabrication, which enable lower manufacturing costs. The need of comparatively complex PECVD deposition systems and the need of hazardous precursors slow down the adoption of heterojunction technology.

A limitation of conventional two-side HIT solar cells is the parasitic light absorption of amorphous silicon layers, which reduces the photocurrent [4]. On the other hand, the absence of high temperature processes makes this technology more processing-friendly with thinner wafers, as opposed to conventional homojunction solar cells. These standard cells also have other limitations such as recombination losses [5] and heavy doping effects [6], which impose a limit on their efficiency.

In the last few years several works have been published aiming to replace doped emitters of classical $\mathrm{Si}$ junctions with alternative materials. The aim is to achieve a "carrier-selective" interface with the absorber [7-9]. The charge separation occurs because one type of charge is blocked while the flow of the opposite one is allowed [10]. The incorporation of such carrier selective heterocontact structures could improve some fundamental limitations of conventional solar cells. Furthermore, most of these materials can be deposited by evaporation or even solution-processed [11]. If these simple technologies could be integrated in a commercial route then higher-efficiency cells could be cost-effectively manufactured. There are different materials reported in the literature that have demonstrated excellent carrier-selective properties on c-Si: organic films $[12,13]$, fluoride salts $[8,14]$ or transition metal oxides (TMOs) $[15,16]$. At present, organic semiconductors are unstable when exposed to the atmosphere and suffer photodegradation effects [17]. For this reason, inorganic alternatives in combination with silicon absorbers are actively researched. Lithium fluoride [8,18], and titanium dioxide [19] layers have been used as electron collectors on n-type $\mathrm{Si}$ substrates, while molybdenum oxide $\left(\mathrm{MoO}_{\mathrm{x}}\right)$ and tungsten oxide $\left(\mathrm{WO}_{\mathrm{x}}\right)$ have been used as hole collectors also for n-type $\mathrm{Si}$ [20-22]. Recently, a conversion efficiency of $22.5 \%$ has been obtained for a solar cell with a $\mathrm{MoO}_{\mathrm{x}}$ hole collector on n-type silicon [23]. However, this device still required a very thin intrinsic amorphous silicon layer between the silicon substrate and the $\mathrm{MoO}_{\mathrm{x}}$ layer for interface passivation.

\footnotetext{
* Corresponding author

E-mail address: rodgar01@ucm.es (R. García-Hernansanz).
} 


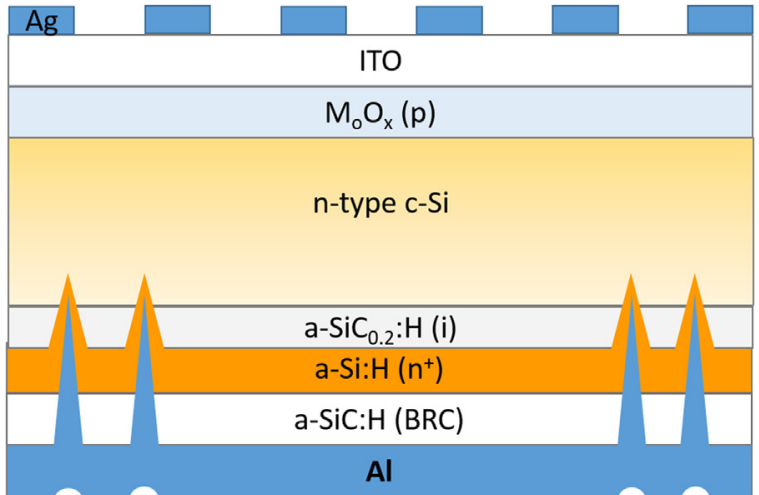

Fig. 1. $\mathrm{MoO}_{\mathrm{x}}$ solar cell structure fabricated for this study. The $\mathrm{MoO}_{\mathrm{x}}$ layer acts as a hole selective contact on n-type silicon.

TMOs have been studied in depth for organic semiconductor devices [24-26], for electronic applications [27,28] and more recently some works have studied these materials deposited on silicon heterojunctions. The physical principles explaining the collection of photogenerated charge-carriers in these devices have been proposed by Battaglia et al. [22]. Nevertheless, a deeper understanding of the mechanisms governing charge-carrier transport without illumination is still needed. An accurate analysis and understanding of the J-V electrical characteristics in dark can provide guidelines to improve the $\mathrm{V}_{\text {oc }}$ values of these devices.

\section{Experimental methods}

In Fig. 1 we present the structure of the $\mathrm{MoO}_{\mathrm{x}}$ heterojunction solar cells studied in this work. The substrate was a double-side polished, $300 \mu \mathrm{m}$ thick, n-type $(2.5 \Omega \mathrm{cm})$ crystalline silicon wafer. First, the substrate was cleaned by a standard RCA cleaning process with a subsequent dip in HF solution (1\%) until it became hydrophobic. Then, it was loaded into a PECVD system to deposit a stack of layers on the rear side. This stack consisted of a $4 \mathrm{~nm}$ intrinsic $\mathrm{a}-\mathrm{SiC}_{\mathrm{x}}: \mathrm{H}(\mathrm{x} \sim 0.2)$ passivation layer and a $15 \mathrm{~nm}$ phosphorous-doped a-Si:H layer. An additional stoichiometric $\mathrm{a}-\mathrm{SiC}_{\mathrm{x}}: \mathrm{H}(\mathrm{x} \sim 1)$ layer was deposited to protect the stack and as a back reflector coating (BRC). Afterwards, the rear side was laser-fired to obtain an array of locally-diffused point contacts with a contacted area ratio of $0.5 \%$. This optimized laser process allows to combine low series resistance with reduced surface recombination at the rear contact [29]. On the front side, after another HF dip, a $15 \mathrm{~nm}$ MoOx layer was thermally evaporated directly on the c-Si substrate, without an a-Si:H passivation layer. We cannot discard the presence a thin interfacial $\mathrm{SiO}_{2}$ layer $(\sim 2 \mathrm{~nm})$ between the $\mathrm{Si}$ substrate and the $\mathrm{MoO}_{\mathrm{x}}$ that grows spontaneously [30]. Subsequently an indium-tin-oxide (ITO) front electrode was deposited by RF magnetron sputtering. Solar cells with $1 \mathrm{~cm}^{2}$ and $4 \mathrm{~cm}^{2}$ active area were defined by a lithographic process and a wet etching of the ITO and MoOx layers. The front electrode is finished by thermally evaporating a $2 \mu \mathrm{m}$ thick silver grid. This electrode covers less than $5 \%$ of the device area. Finally, the rear electrode consisted in a $1 \mu \mathrm{m}$ thick aluminium layer evaporated on the laser-fired contacts.

The current density as a function of applied voltage ( $\mathrm{J}-\mathrm{V}$ characteristic) was measured with an Agilent 2400 SourceMeter. The J-V curves were measured in darkness and under 1-sun AM1.5 illumination with an ORIEL 94021A (Newport) solar simulator. The light irradiance was properly calibrated by means of a pyrometer. The external quantum efficiency curve was measured using a commercial instrument QEX10 from PV Measurements. After the initial room temperature characterization, the solar cell was mounted inside the chamber of a closed-loop helium cryostat, which controls temperature with an additional heater. Then, J-V characteristics in darkness were measured at temperatures from $360 \mathrm{~K}$ to $220 \mathrm{~K}$. All these electrical measurements were done in a 4 wire configuration to minimize the contribution of the copper cables to the series resistance. The well-known two-diode model was used to fit the measured $\mathrm{J}-\mathrm{V}$ curves $[31,32]$ according to the following expression:

$$
\begin{aligned}
& J=J_{D 1}+J_{D 2}+J_{\text {SHUNT }} \\
& J=J_{0,1}(T)\left[e^{A_{1}(T)\left(V-J R_{S}\right)}-1\right]+J_{0,2}(T)\left[e^{A_{2}(T)\left(V-J R_{S}\right)}-1\right]+\frac{V-J R_{S}}{R_{\text {Shunt }}}
\end{aligned}
$$

In this expression $J_{D 1}$ and $J_{D 2}$ correspond to the two main conduction mechanisms, where $J_{O, 1}(T)$ and $J_{O, 2}(T)$ are the saturation current densities and $A_{1}(T), A_{2}(T)$ are the exponential factors of each mechanism. Also, the parasitic series resistance $R_{S}$ and parallel resistance $R_{\text {Shunt }}$ were considered in the equivalent circuit. We can determine the different conduction mechanisms by studying the temperature dependences of the fitting parameters of Eq. (1). It is known that the saturation current density and the exponential factor will adjust to the following expressions $[33,34]$ :

$J_{0, i}=J_{0,0, i} \cdot \frac{\frac{-E_{a, i}}{k T}}{k}$

$A_{i}(T)=\frac{q}{n_{i} k T}$

where $E_{a, i}$ is the activation energy of each mechanism and $n_{i}$ the corresponding diode ideality factor. Finally, to analyse the electrical characteristics measured at reverse bias polarization we used the following equation $[31,35]$ :

$J_{R}=J_{r e v, 0} e^{\left(-\frac{E_{a, r e v}}{K T}\right)}\left(V_{D}-V\right)^{b}$

where $J_{r e v, 0}$ is a base current, $V_{D}$ a constant voltage, $E_{a, r e v}$ an activation energy of the process and $b$ is a temperature independent coefficient.

\section{Results and discussion}

Fig. 2 shows the EQE and J-V characteristic curve of a representative $\mathrm{MoO}_{\mathrm{x}}$ based solar cell at room temperature under 1-sun illumination. All the fabricated devices showed a similar behaviour, either for $1 \mathrm{~cm}^{2}$ or $4 \mathrm{~cm}^{2}$ cells. These solar cells have a $\mathrm{V}_{\mathrm{OC}}=614 \mathrm{mV}$, $\mathrm{J}_{\mathrm{SC}}=32,8 \mathrm{~mA} / \mathrm{cm}^{2}$ and F.F. $=73.2 \%$, resulting in a photovoltaic conversion efficiency of $14.7 \%$. To our knowledge this is the best efficiency reported for a direct heterojunction between $\mathrm{MoO}_{\mathrm{x}}$ and n-type c$\mathrm{Si}$ without passivation layers. The $\mathrm{V}_{\mathrm{OC}}$ and F.F. values are significantly higher than those previously reported [9]. The Jsc value is lower in our cells, but is rather good for a non-textured surface.

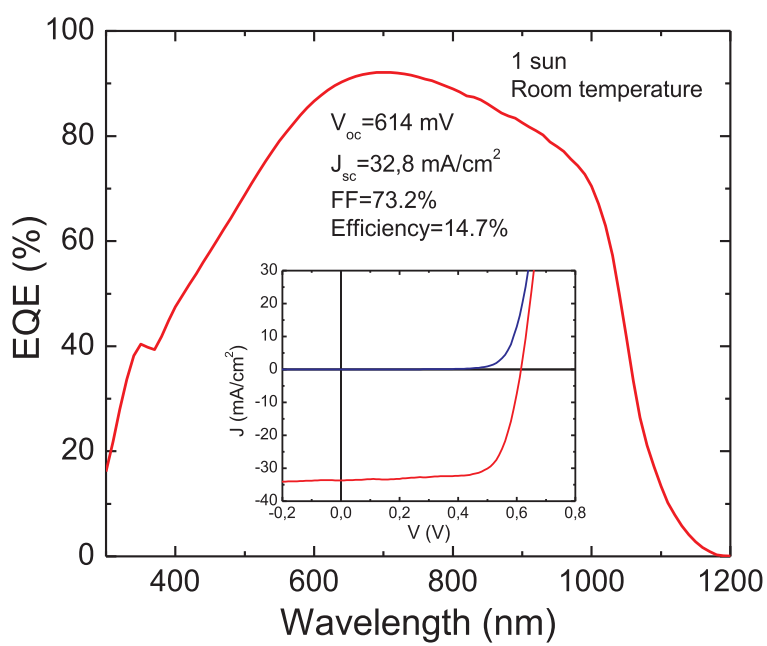

Fig. 2. $\mathrm{J}-\mathrm{V}$ and EQE characteristic of $\mathrm{a} \mathrm{MoO}_{\mathrm{x}}$ based solar cell under illumination at 1 sun at room temperature. 


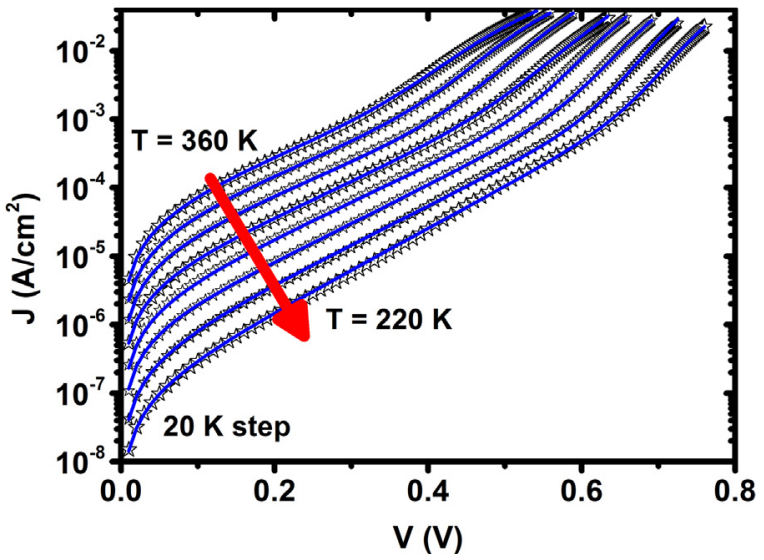

Fig. 3. Dark J-V characteristics of the solar cell, measured (stars) and fitted (blue lines), at different temperatures, from $360 \mathrm{~K}$ to $220 \mathrm{~K}$. The black arrow goes from the highest temperature in this study $(360 \mathrm{~K})$ to the lowest $(220 \mathrm{~K})$. The temperature difference between consecutive curves is $20 \mathrm{~K}$. (For interpretation of the references to color in this figure legend, the reader is referred to the web version of this article.)

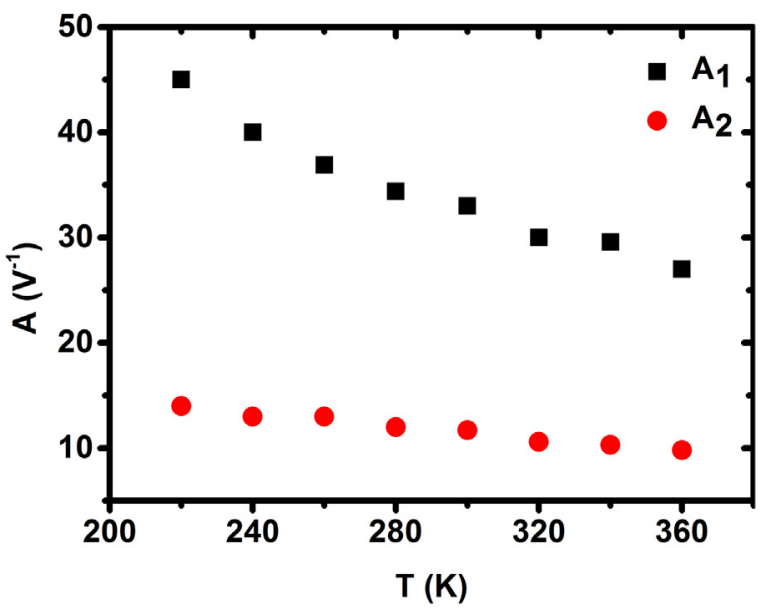

Fig. 4. Exponential factor for the two conduction mechanisms predominant in the solar cell. We can observe a temperature dependence in $A_{1}(T)$ for the high voltage process while the low voltage process $\mathrm{A}_{2}(\mathrm{~T})$ remains almost constant.

In Fig. 3 we present the forward $\mathrm{J}-\mathrm{V}$ characteristics in darkness of a representative $1 \mathrm{~cm}^{2} \mathrm{MoO}_{\mathrm{x}}$ based solar cell measured from $360 \mathrm{~K}$ to $220 \mathrm{~K}$, at intervals of $20 \mathrm{~K}$. In the same figure the blue lines represent the curves fitted to Eq. (1) for each temperature. We can observe the good agreement between the measurements and the fitted curves in all the temperature range. At high bias the effect of series resistance is observed, with values lower than $2 \Omega \mathrm{cm}^{2}$ for all curves. The shunt resistance is not observed in any of the curves measured under dark conditions. The curves present clearly two different slopes, at low bias $(V<0.4-0.6 \mathrm{~V}$ depending on the temperature) and at high bias $(V>0.4-0.6 \mathrm{~V})$. This indicates that two different conduction mechanisms with exponential behaviour are taking place. In Fig. 4 we plot the parameters $A_{1}(T)$ (high voltage range) and $A_{2}(T)$ (low voltage range) obtained from the fittings. While $A_{1}(T)$ has a strong temperature dependence, $A_{2}(T)$ remains roughly constant. Fitting the high voltage mechanism to Eq. (3) we obtain a constant diode factor of $n_{1}$ $=1.20 \pm 0.09$. On the other hand, if the same equation is used to fit $A_{2}(T)$ the obtained diode factor value is between 3 and 4 depending on temperature. The diode ideality factor, which is deduced from dark electrical characteristics, indeed has influence on the solar cell efficiency. A high n-value not only degrades the FF, but it is also a signal of higher recombination. Therefore, low open-circuit voltages are

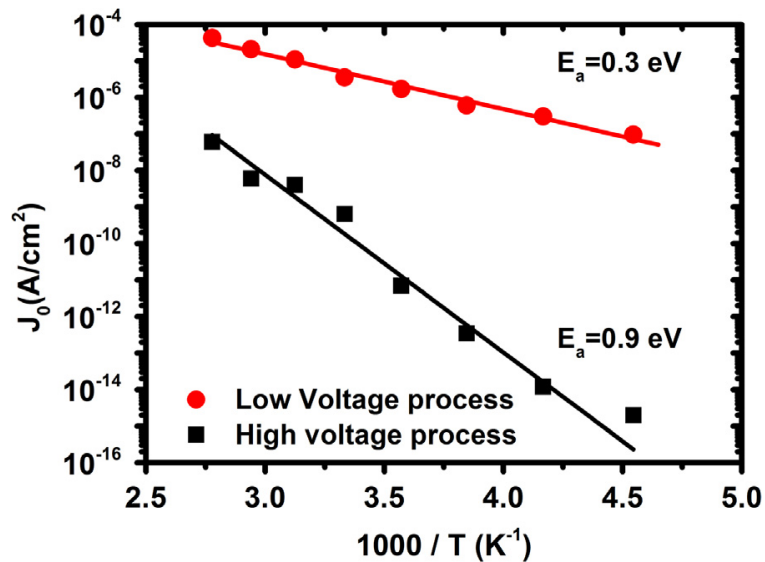

Fig. 5. Saturation current as a function of $1000 / \mathrm{T}$ for both mechanisms. We obtained an activation energy of $\mathrm{E}_{\mathrm{a}}=0.90 \pm 0.06 \mathrm{eV}$ and $\mathrm{E}_{\mathrm{a}}=0.30 \pm 0.01 \mathrm{eV}$ for each process.

expected, and as a consequence, low solar cell efficiency. In fact, as the diode ideality factor increases (from the ideal value of $n=1$ ), the voltage at the maximum power point decreases, and therefore the efficiency of the device [36]. Since the $\mathrm{V}_{\mathrm{OC}}$ value of our cells is $614 \mathrm{mV}$, their efficiency will be determined by the dominant transport mechanism around these voltage values, that is the one with $n_{1}=1.20$. Therefore, better efficiencies could be obtained by reducing the ideality factor closer to $\mathrm{n}=1$ for the high bias transport mechanism. Concerning the other mechanism observed in the $\mathrm{J}-\mathrm{V}$ characteristics at lower bias, a temperature-dependent ideality factor is common for trapassisted tunnelling processes [37]. Such a temperature dependence can be related to an interface state density distribution [38,39], quantum mechanical tunnelling $[39,40]$ or image force lowering [40]. In Fig. 5 we present the Arrhenius plots of the saturation current densities related to the high and low voltage processes. An activation energy $\left(E_{a}\right)$ of $0.90 \mathrm{eV}$ was obtained for the high voltage mechanism and an $E_{a}$ $=0.30 \mathrm{eV}$ was obtained for the low voltage one. These values clearly differ from a typical recombination diode and must be explained by other mechanisms. The high values of $n_{2}$, together with the moderate temperature dependence of $A_{2}$ and the $E_{a}$ value of $0.3 \mathrm{eV}$, suggest that at low voltage the current is dominated by a tunnelling process $[31,35]$.

In order to support this conclusion we analysed the electrical characteristics measured under reverse bias. In Fig. 6 we represent ln $\left(J_{R}\right)$ vs $\ln (V)$ and these data are fitted to Eq. (4). A linear behaviour with very similar slope (b in Eq. (4)) is obtained for all measurements in

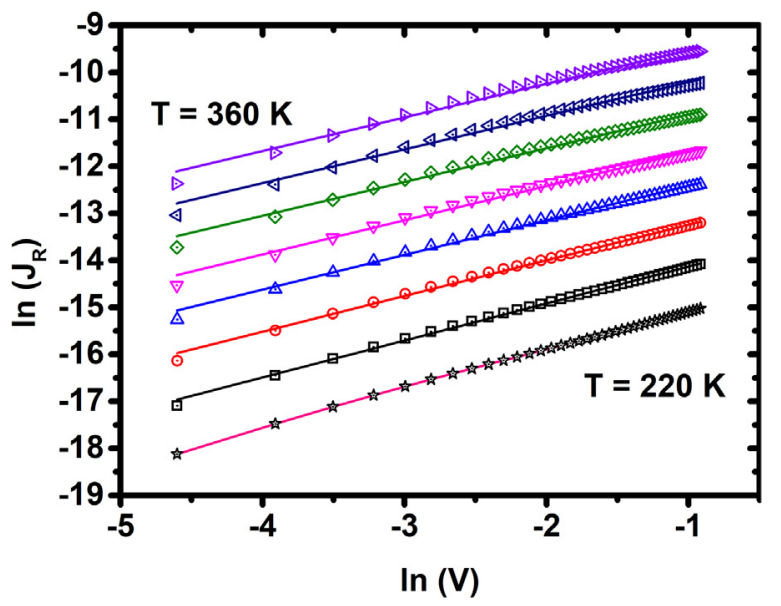

Fig. 6. Reverse bias characteristic under dark conditions, for temperatures from $360 \mathrm{~K}$ to $220 \mathrm{~K}$ in $20 \mathrm{~K}$ steps. The respective fits (lines) were calculated using Eq. (4). 


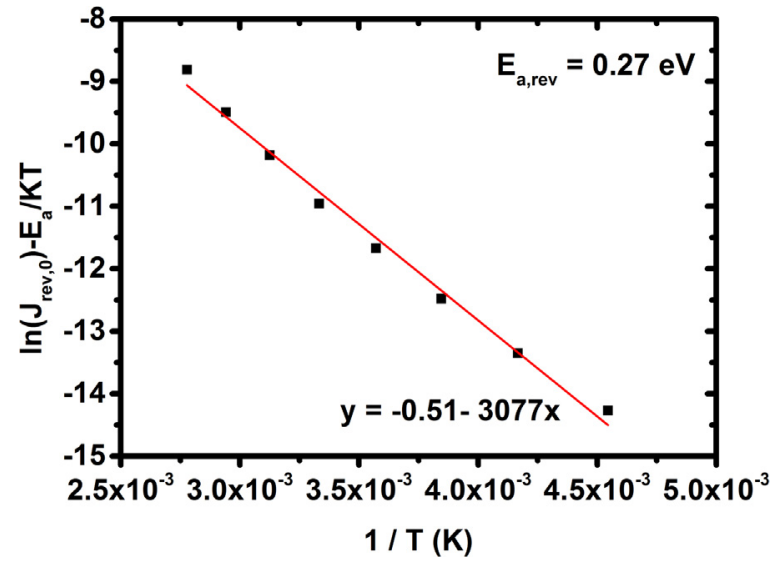

Fig. 7. Ordinate intercept of the fittings of Eq. (4) as a function of $1 / \mathrm{T}$ for the temperature range used in this study. We obtained an activation energy of $E_{a}$ $=0.27 \pm 0.01 \mathrm{eV}$.

the studied temperature range. The approximately constant value obtained for the slope is $\mathrm{b}=0.74 \pm 0.03$. By contrast, the intercept with the ordinate axis (when $\ln (\mathrm{V})=0$ ) shows a temperature dependence. In Fig. 7 we represent each intercept with the ordinate axis as a function of $1 / T$, and the linear fitting which results in an activation energy of $\mathrm{E}_{(\mathrm{a}, \mathrm{rev})}=0.27 \mathrm{eV}$. This value for the activation energy, within experimental error, points to the same tunnel mechanism observed at low forward bias. These results are very relevant because the current measured in dark under reverse bias has the same direction as it has under illumination at low forward bias. Therefore, the conduction mechanisms taken place should be the same.

To explain these results, in Fig. 8 we present a qualitative band diagram of a $\mathrm{MoO}_{\mathrm{x}}$ heterojunction solar cell, which can help to understand the conduction mechanisms of these devices. This figure is based on the band diagrams presented in Refs. [22,41,42]. The high work function of the $\mathrm{MoO}_{\mathrm{x}}$ [16] produces a large band bending of the $\mathrm{n}$ type silicon surface. In fact, an inversion layer appears at the interface with a hole concentration larger than the substrate doping concentration [21]. This p-type inversion layer near the surface is shown as the yellow region in Fig. 8. Furthermore, the $\mathrm{MoO}_{\mathrm{x}}$ presents a high density of oxygen vacancies, which results in a quasi-continuous distribution of energy levels within its bandgap. In fact, Battaglia et al. [22] describe this quasi-continuous distribution of energy levels as a defect band.

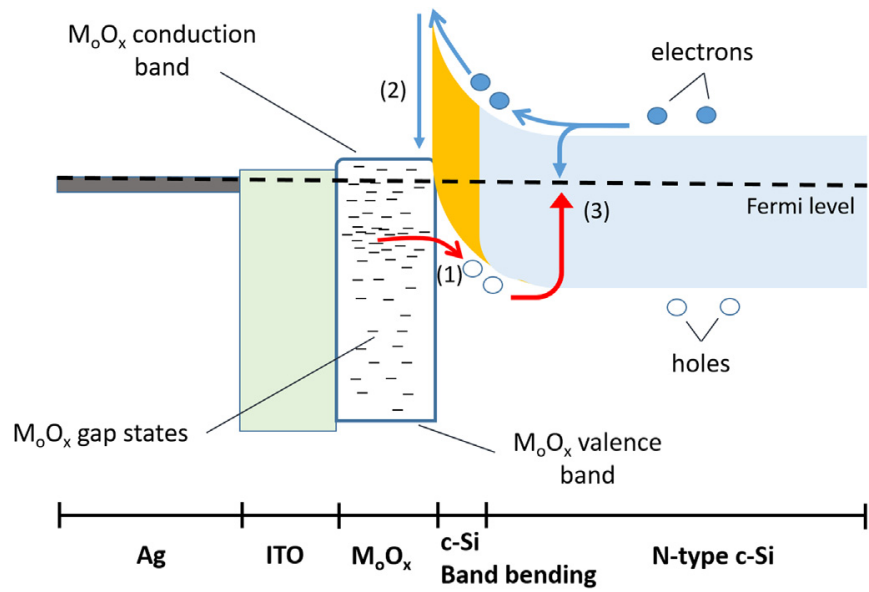

Fig. 8. Proposed equilibrium band diagram of a $\mathrm{MoO}_{\mathrm{x}}$ silicon based solar cell and the current transport mechanisms identified with numbers: (1) tunnelling mechanism, (2) Schottky barrier, (3) diffusion/recombination mechanism. The observed tunnel in reverse bias is the same than (1), but in the opposite direction.
Other authors have referred to these gap states as a "quasi-conduction band" for oxides [28]. These states in the bandgap seem to play a capital role to explain the good hole injection and extraction properties of the $\mathrm{MoO}_{\mathrm{x}}$ layer.

It has been suggested that the passivating behaviour of the MoOx layer is due to the spontaneous formation of an ultrathin $\mathrm{SiO}_{\mathrm{x}}$ layer [30] between the Si substrate and the $\mathrm{MoO}_{\mathrm{x}}$. Since all the currents must flow across this $\mathrm{SiO}_{\mathrm{x}}$ layer, the observed tunnelling mechanism in the $\mathrm{J}-\mathrm{V}$ characteristic cannot be explained by processes within the $\mathrm{SiO}_{\mathrm{x}}$. If that were the case, such tunnelling process would limit the current in the whole voltage range. Because of this, we conclude that the observed tunnelling process consists of holes transported across the MoOx gap states, labelled by (1) in Fig. 8. This tunnelling process is similar to that explained by Schulze et al. [31] for a-Si/c-Si heterojunction solar cells using the multitunnelling capture emission (MTCE) theory, where carriers from the c-Si tunnel into states within the amorphous silicon bandgap and then recombine through carrier capture or reemission. The saturation current density in MTCE is exponentially dependent on 1/T following an expression similar to Eq. (2). [43]. The activation energy of $E_{a}=0.30 \pm 0.01 \mathrm{eV}$ obtained from Fig. 5 by fitting the Arrhenius plot is consistent with the MTCE values reported in the study for different heterojunctions on silicon $[31,44]$. The agreement between experimental results and the MTCE model supports our explanation of a tunnelling process dominant at low voltages.

On the other hand, there are two processes that could be related with a diode factor of $n_{1}=1.20$ and an activation energy of $0.90 \mathrm{eV}$ : diffusion/recombination in the silicon bulk (labelled by (3) in Fig. 8) and the transport of electrons between the $\mathrm{c}-\mathrm{Si}$ and $\mathrm{MoOx}$ conduction bands (labelled by (2) in Fig. 8). Although the obtained values are coherent with diffusion/recombination values reported for silicon heterojunctions [31], we believe that this cannot be the observed process. According to Fig. 3, the low voltage tunnelling process and this high voltage process operate in parallel, adding both currents. However, as it can be observed in Fig. 8, any transport process involving hole diffusion into the n-type c-Si would be in series with the hole tunnelling across the MoOx. The same applies for any process involving the recombination of electrons coming from the c-Si before they reach the MoOx. The only conduction process in parallel with the hole MoOx tunnelling is the injection of electrons from the c-Si over the barrier voltage into the MoOx conduction band.

As it can observed in Fig. 8, this structure is similar to a Schottky junction with a high barrier value due to the high MoOx work function. The strong inversion induced at the silicon surface explains the high activation energy of $0.9 \mathrm{eV}$. Concerning the diode ideality factor, a value of $\mathrm{n}=1.20$ is higher than that expected for Schottky barriers $(n=1)$. This higher value could be related with a voltage drop across the MoOx, and therefore it depends on its thickness [45].

\section{Conclusions}

We have fabricated a set of $\mathrm{MoO}_{\mathrm{x}}$ solar cells with conversion efficiency of $14.7 \%, \mathrm{~V}_{\mathrm{OC}}=614 \mathrm{mV}, \mathrm{J}_{\mathrm{SC}}=32,8 \mathrm{~mA} / \mathrm{cm}^{2}$ and F.F. $=73.2 \%$. These values are lower than the state-of-the-art, but among the highest reported for direct $\mathrm{MoO}_{\mathrm{x}} / \mathrm{n}$-type c-Si heterojunctions without any additional passivation layer. From the dark J-V characteristics as a function of temperature, two different transport processes were identified: a Schottky behaviour process with an ideality factor $\mathrm{n}_{1}=1.20$, and a tunnelling process characterized by an ideality factor $n_{2}$ with values in the 3-4 range. This tunnelling process determines the electrical characteristic at low voltages. The exponential dependence of the saturation current density as a function of $1000 / \mathrm{T}$ suggests a multitunnelling capture emission process. We obtained an activation energy $E_{a}=0.30 \pm 0.01 \mathrm{eV}$ for this mechanism, which agrees with the MTCE model for silicon heterojunctions. Finally, when biased at high voltages and at usual operation temperatures, the current of these devices is mainly determined by the barrier between the $\mathrm{MoOx}$ 
and the c-Si conduction bands.

\section{Acknowledgements}

Authors would like to acknowledge the CAI de Técnicas Físicas of the Universidad Complutense de Madrid for the use of its laboratories. This work was partially supported by the Project MADRID-PV (Grant No. 2013/MAE-2780) funded by the Comunidad de Madrid, by the Spanish MINECO (Ministerio de Economía y Competitividad) under grants TEC 2013-41730-R, TEC2017-84378-R and ENE2016-78933-C41-R. Also by the Universidad Complutense de Madrid (Programa de Financiación de Grupos de Investigación UCM-Banco Santander) under grant 910173-2014. D. Montero acknowledges the Spanish MINECO (Ministerio de Economía y Competitividad) for financial support under contract BES-2014-067585 and L.G. Gerling the support from Mexico's grant program CONACyT.

\section{References}

[1] K. Yoshikawa, H. Kawasaki, W. Yoshida, T. Irie, K. Konishi, K. Nakano, et al., Silicon heterojunction solar cell with interdigitated back contacts for a photoconversion efficiency over 26\%, Nat. Energy 2 (2017) 17032.

[2] W. Shockley, H.J. Queisser, Detailed balance limit of efficiency of p-n junction solar cells, J. Appl. Phys. 32 (1961) 510.

[3] M.A. Green, K. Emery, Y. Hishikawa, W. Warta, E.D. Dunlop, D.H. Levi, et al., Solar cell efficiency tables (version 49), Prog. Photovolt. 25 (2017) 3-13.

[4] Z.C. Holman, A. Descoeudres, L. Barraud, F.Z. Fernandez, J.P. Seif, S. De Wolf, et al., Current losses at the front of silicon heterojunction solar cells, IEEE J. Photovolt. 2 (2012) 7-15.

[5] A. Richter, S.W. Glunz, F. Werner, J. Schmidt, A. Cuevas, Improved quantitative description of Auger recombination in crystalline silicon, Phys. Rev. B 86 (2012) 165202.

[6] A. Cuevas, P.A. Basore, G. GiroultMatlakowski, C. Dubois, Surface recombination velocity of highly doped n-type silicon, J. Appl. Phys. 80 (1996) 3370-3375.

[7] J. Bullock, M. Hettick, J. Geissbuhler, A.J. Ong, T. Allen, C.M. Sutter-Fella, et al., Efficient silicon solar cells with dopant-free asymmetric heterocontacts, Nat. Energy 1 (2016) 15031

[8] J.-H. Yang, H.-H. Jung, J. Seo, K.-D. Kim, D.-H. Kim, D.-C. Lim, et al., Dopant-free hydrogenated amorphous silicon thin-film solar cells using molybdenum oxide and lithium fluoride, J. Phys. Chem. C 117 (2013) 23459-23468.

[9] C. Battaglia, X. Yin, M. Zheng, I.D. Sharp, T. Chen, S. McDonnell, et al., Hole selective MoOx contact for silicon solar cells, Nano Lett. 14 (2014) 967-971.

[10] U. Wuerfel, A. Cuevas, P. Wuerfel, Charge carrier separation in solar cells, IEEE J. Photovolt. 5 (2015) 461-469.

[11] J. Tong, Y. Wan, J. Cui, S. Lim, N. Song, A. Lennon, Solution-processed molybdenum oxide for hole-selective contacts on crystalline silicon solar cells, Appl. Surf. Sci. 423 (2017) 139-146.

[12] D. Zielke, A. Pazidis, F. Werner, J. Schmidt, Organic-silicon heterojunction solar cells on n-type silicon wafers: the Back PEDOT concept, Sol. Energy Mater. Sol. Cells 131 (2014) 110-116.

[13] D. Zielke, C. Niehaves, W. Loevenich, A. Elschner, M. Hoerteis, J. Schmidt, Organicsilicon solar cells exceeding 20\% efficiency, Proceedings of the 5th International Conference on Silicon Photovoltaics, Siliconpv 2015, 77, 2015, pp. 331-339.

[14] Y. Wan, C. Samundsett, J. Bullock, T. Allen, M. Hettick, D. Yan, et al., Magnesium fluoride electron-selective contacts for crystalline silicon solar cells, ACS Appl. Mater. Interfaces 8 (2016) 14671-14677.

[15] M. Bivour, J. Temmler, H. Steinkemper, M. Hermle, Molybdenum and tungsten oxide: high work function wide band gap contact materials for hole selective contacts of silicon solar cells, Sol. Energy Mater. Sol. Cells 142 (2015) 34-41.

[16] J. Meyer, S. Hamwi, M. Kroeger, W. Kowalsky, T. Riedl, A. Kahn, Transition metal oxides for organic electronics: energetics, device physics and applications, Adv. Mater. 24 (2012) 5408-5427.

[17] M. Jorgensen, K. Norrman, F.C. Krebs, Stability/degradation of polymer solar cells, Sol. Energy Mater. Sol. Cells 92 (2008) 686-714.

[18] H.-D. Um, N. Kim, K. Lee, I. Hwang, J.H. Seo, K. Seo, Dopant-free all-back-contact Si nanohole solar cells using MoOx and LiF films, Nano Lett. 16 (2016) 981-987.

[19] K.A. Nagamatsu, S. Avasthi, G. Sahasrabudhe, G. Man, J. Jhaveri, A.H. Berg, et al., Titanium dioxide/silicon hole-blocking selective contact to enable double- heterojunction crystalline silicon-based solar cell, Appl. Phys. Lett. 106 (2015) 123906.

[20] L.G. Gerling, S. Mahato, C. Voz, R. Alcubilla, J. Puigdollers, Characterization of transition metal oxide/silicon heterojunctions for solar cell applications, Appl. Sci. -Basel 5 (2015) 695-705.

[21] J. Bullock, A. Cuevas, T. Allen, C. Battaglia, Molybdenum oxide MoOx: a versatile hole contact for silicon solar cells, Appl. Phys. Lett. 105 (2014) 232109.

[22] C. Battaglia, S.M. de Nicolas, S. De Wolf, X. Yin, M. Zheng, C. Ballif, et al., Silicon heterojunction solar cell with passivated hole selective MoOx contact, Appl. Phys. Lett. 104 (2014) 113902.

[23] J. Geissbuehler, J. Werner, S.M. de Nicolas, L. Barraud, A. Hessler-Wyser, M. Despeisse, et al., 22.5\% efficient silicon heterojunction solar cell with molybdenum oxide hole collector, Appl. Phys. Lett. 107 (2015) 081601.

[24] S.R. Hammond, J. Meyer, N.E. Widjonarko, P.F. Ndione, A.K. Sigdel, A. Garcia, et al., Low-temperature, solution-processed molybdenum oxide hole-collection layer for organic photovoltaics, J. Mater. Chem. 22 (2012) 3249-3254.

[25] J. Meyer, A. Kahn, Electronic structure of molybdenum-oxide films and associated charge injection mechanisms in organic devices, J. Photon. Energy 1 (2011) 011109.

[26] K.H. Wong, K. Ananthanarayanan, J. Luther, P. Balaya, Origin of hole selectivity and the role of defects in low-temperature solution-processed molybdenum oxide interfacial layer for organic solar cells, J. Phys. Chem. C 116 (2012) 16346-16351.

[27] Z.Q. Liu, D.P. Leusink, X. Wang, W.M. Lu, K. Gopinadhan, A. Annadi, et al., Metalinsulator transition in $\mathrm{SrTiO}_{3}$-x thin films induced by frozen-out carriers, Phys. Rev. Lett. 107 (2011) 146802.

[28] Z.Q. Liu, D.P. Leusink, W.M. Lu, X. Wang, X.P. Yang, K. Gopinadhan, et al., Reversible metal-insulator transition in $\mathrm{LaAlO}_{3}$ thin films mediated by intragap defects: an alternative mechanism for resistive switching, Phys. Rev. B 84 (2011) 165106.

[29] M. Colina, A.B. Morales-Vilches, C. Voz, I. Martin, P.R. Ortega, R. Alcubilla, Low surface recombination in silicon-heterojunction solar cells with rear laser-fired contacts from aluminum foils, IEEE J. Photovolt. 5 (2015) 805-811.

[30] L.G. Gerling, C. Voz, R. Alcubilla, J. Puigdollers, Origin of passivation in hole-selective transition metal oxides for crystalline silicon heterojunction solar cells, J. Mater. Res. 32 (2017) 260-268.

[31] T.F. Schulze, L. Korte, E. Conrad, M. Schmidt, B. Rech, Electrical transport mechanisms in a-Si: H/c-Si heterojunction solar cells, J. Appl. Phys. 107 (2010) 023711.

[32] L.F. Marsal, J. Pallares, X. Correig, J. Calderer, R. Alcubilla, Electrical character ization of n-amorphous/p-crystalline silicon heterojunctions, J. Appl. Phys. 79 (1996) 8493-8497.

[33] W. Shockley, The theory of p-n junction in semiconductors and p-n junctions transistors, Bell Syst. Tech. J. 28 (1949) 435-489.

[34] C.T. Sah, R.N. Noyce, W. Shockley, Carrier generation and recombination in p-n junctions and p-n junction characteristics, in: Proceedings of the Institute of Radio Engineers, 45, 1957, pp. 1228-1243.

[35] H. Matsuura, T. Okuno, H. Okushi, K. Tanaka, Electrical properties of n-amorphous p-crystalline silicon heterojunctions, J. Appl. Phys. 55 (1984) 1012-1019.

[36] A. Vasic, M. Stojanovic, P. Osmokrovic, N. Stojanovic, The influence of ideality factor on fill factor and efficiency of solar cells, Trends Adv. Mater. Process. 352 (2000) 241-245.

[37] S. Altindal, S. Karadeniz, N. Tugluoglu, A. Tataroglu, The role of interface states and series resistance on the $\mathrm{I}-\mathrm{V}$ and $\mathrm{C}-\mathrm{V}$ characteristics in $\mathrm{Al} / \mathrm{SnO}_{2} / \mathrm{p}-\mathrm{Si}$ Schottky diodes, Solid-State Electron. 47 (10) (2003) 1847-1854.

[38] R.T. Tung, Electron-transport at metal-semiconductor interfaces- general tehory, Phys. Rev. B 45 (23) (1992) 13509-13523.

[39] C.R. Crowell, Physical significance of to anomalies in Schottky barriers, Solid-State Electron. 20 (3) (1977) 171-175.

[40] E.H. Rhoderick, R.H. Williams, Metal-semiconductors Contacts, ed., Clarendon press, 1988.

[41] L.G. Gerling, S. Mahato, A. Morales-Vilches, G. Masmitja, P. Ortega, C. Voz, et al., Transition metal oxides as hole-selective contacts in silicon heterojunctions solar cells, Sol. Energy Mater. Sol. Cells 145 (2016) 109-115.

[42] T. Sun, R. Wang, R. Liu, C. Wu, Y. Zhong, Y. Liu, et al., Investigation of MoOx/n-Si strong inversion layer interfaces via dopant-free heterocontact, Phys. Status SolidiRapid Res. Lett. 11 (2017) 1700107.

[43] A.R. Riben, D.L. Feucht, NGE-PGAAS heterojunctions, Solid-State Electron. 9 (1966) (1055-\&).

[44] L.F. Marsal, I. Martin, J. Pallares, A. Orpella, R. Alcubilla, Annealing effects on the conduction mechanisms of $\mathrm{p}(+)$-amorphous-Si0.8C0.2: H/n-crystalline-si diodes, $\mathrm{J}$. Appl. Phys. 94 (2003) 2622-2626.

[45] H.C. Card, E.H. Rhoderick, Studies of tunnel MOS diodes .1. interface effects in silicon schottky diodes, J. Phys. D-Appl. Phys. 4 (1971) 1589. 